\title{
Using agro-hydrology to adapt to climate evolutions
}

\author{
A. Degré, C. Sohier, A. Bauwens \& M. Grandry \\ Univ. Liège - Gembloux Agro-Bio Tech, Soil-Water Systems, Gembloux, Belgium
}

\begin{abstract}
Natural phenomena such as floods, drought, erosion, nitrate leaching and plant growth are influenced by climate change. The Soil - Water Systems division of Gembloux Agro-Bio Tech aims at studying these phenomena; better understanding processes; modelling them in order to predict their change in the future and to assess their potential consequences. Then, we can propose strategies to adapt to these changes. As an agronomy faculty, we believe that adapting agriculture can play a major role in mitigating climate evolution effects at plot and catchment scales.
\end{abstract}

Soil - Water Systems is a division of the department of Environmental Sciences and Technologies of Gembloux Agro-Bio Tech (GxABT), the agronomy faculty of the University of Liège (B). Environmental management is, in fact, one of the two main research topics of the faculty, the other one being the valorisation of bioproducts, both linked with the production of bioresources. Management plans of arable, forested and natural lands proposed by GxABT will take into account global change (climate change, land use changes and urbanisation). Therefore, within the Soil - Water Systems division, projects focus on the link between hydrology and agriculture, taking account of climate change. Indeed, climate change disturbs most natural phenomena and it is important to quantify and mitigate these impacts.

As a partner of the AMICE project, we have contributed to the study of the hydrological effects of climate change on the Meuse catchment and developed a methodology to evaluate its impacts on the Mosan agriculture. Results have shown that both winter high flows and summer low flows could be exacerbated. Studying these extreme conditions is thus essential. Consequences on the agricultural sector can be both positive and negative, depending on the range of predicted changes and the adaptation capacity of agricultural systems. We have found that, in the Meuse catchment, yields would increase for wheat, barley and grasslands but decrease for corn. However, the variability in yields would rise in the future. The study has also revealed that the different crops would start growing and reach maturity earlier. Agricultural systems will therefore need to be adapted (e.g. adaptation of the cultural calendar by moving forward the seeding and harvesting dates) (Drogue et al. 2010, Bauwens et al 2011).

The simulations for this study were performed with a physically-based model able to simulate the water-soil-plant continuum (derived from the EPIC model). The EPIC model has actually been adapted to the Walloon Region (EPICgrid) and has also been used to model nitrate concentration in the recharge water. EPICgrid has allowed us to evaluate diffuse nitrate pollution and the efficiency of present and further mitigation measures. Simulations results have shown that current measures to reduce the effect of diffuse pollution on water quality are not sufficient in some areas and that new actions are necessary. Scenarios including modifications of agricultural practices, such as a change in crop rotations or a decrease in the use of mineral fertilisers, have shown significant effects on water quality. Nevertheless, due to transfer time through the vadose zone (more than 20 years in some subregions), it was shown that an increase in groundwater nitrate concentrations will occur until at least 2030 for some regions before new agricultural prac- 
tices can impact groundwater quality positively. Moreover, an increase in nitrate leaching in the future due to longer saturation periods in autumn and winter has been found under the wet scenario (Sohier et al. 2009, Sohier 2011).

Yet, these results have to be taken with caution since future climate is uncertain. For example, the evolution of precipitation quantity is not known with certainty. Nevertheless, it has been demonstrated that rainfall intensity will increase, causing more erosion and soil and nutrient losses. In our division, a study has measured the effects of different agricultural practices on erosion and runoff under a future rainfall. On a field cultivated with sugar beets, contrasted tillage practices were tested. Simplified tillage with decompaction produces less soil losses, while winter ploughing gives the lowest runoff quantities comparing with fall ploughing and soil decompaction. For a corn crop, distributed seeding (obtained with a seeder) gives the lowest rates of both soil losses and runoff quantities, comparing with classic seeding (75-cm interrow) and classic seeding with Ray-grass seeding between the rows (Kummert et al. 2011).

As we can see, modelling is really useful to represent systems and predict future conditions. But it is also important to perform field measurements in order to better understand and quantify processes. That is why we are also monitoring the spatial distribution of erosion and deposition on a pilot catchment. Instrumentation includes a weather station with disdrometer and discharge measurement at the outlet coupled with water sampling. Field observations are done to determine the texture redistribution. Moreover, very accurate digital elevation models will be obtained regularly using Lidar technology, which will allow us to follow the evolution of the topography. Then, we aim at modelling both erosion and sedimentation on this catchment, and estimating net erosive flows, taking climate change into consideration. This will help us find strategies to limit erosion and runoff from their source (Pineux \& Degré 2012a).

Our research answers concrete needs from managers of rural areas and rivers. The implementation of European directives in the environmental field and, especially, in water management, generates a request from policy makers for new tools. Flood maps taking into account overland flows and mudflows in addition to river overflowing have been produced as part of the implementation of the Floods Directive in Wallonia. Indeed, on top of loss of arable land, runoff can cause great damage to property and deteriorate water quality in watercourses (Pineux \& Degré 2012b). EPICgrid was used to evaluate diffuse pollution and the efficiency of mitigation measures in the context of the Nitrate Directive. The knowledge of river behaviour during low flows is also important nowadays for a good integrated management of rivers (managing water quality in regards to the Water Framework Directive, biodiversity, water resources, etc.). Another study has allowed water managers to calculate low flow discharges (MAM7 i.e. Mean Annual Minimum flow on a 7-day average basis) in any ungauged catchments of Wallonia for different return periods (Grandry et al. 2012).

In conclusion, all these natural phenomena (floods, drought, erosion, mudflows, nitrate leaching, etc) will be affected by climate change and especially by extreme conditions. But they can also be influenced by humans. We need to adapt, and measures have to be taken in order to reduce negative effects of climate evolution and take the best of the potential positive effects. We believe that adapting agriculture can play a major role in mitigation at plot and catchment scales.

\section{REFERENCES}

Bauwens, A., Sohier, C. \& Degré, A. 2011. http://hdl.handle.net/2268/91848.

Drogue, G. et al., 2010. http://hdl.handle.net/2268/68472.

Grandry, M., Gailliez, S., Sohier, C., Verstraete, A. \& Degré, A. 2012. A method for low flow estimation at ungauged sites, case study in Wallonia (Belgium). Hydrol. Earth Syst. Sci. Discuss. 9:11583-11614.

Kummert, N., Beckers, E. \& Degré, A. 2011. http://hdl.handle.net/2268/83320.

Sohier, C., Degré, A. \& Dautrebande, S. 2009. http://hdl.handle.net/2268/16572.

Sohier C. 2011. http://hdl.handle.net/2268/86912.

Pineux, N. \& Degré, A. 2012a. http://hdl.handle.net/2268/128148.

Pineux, N. \& Degré, A. 2012b. http://hdl.handle.net/2268/120911. 